\title{
Editorial: Going monthly
}

The number of scientific papers submitted to medical journals grows steadily year by year. Despite stricter refereeing and insistence on succinctness of presentation, some of this excess has to be accommodated by the founding of new journals and by increasing the size of existing journals or producing them more frequently. All these processes have been taking place in rheumatology recently. Readers of the Annals will have noticed the lengthening table of contents and-more seriously - that the backlog of stacked-up papers had produced a delay in publication time which was unacceptably long. For this reason the Annals will from this number appear monthly. The backlog of manuscripts was eliminated by increasing the size of recent numbers, so this switch to monthly publication should make it possible to maintain a reasonable publication time for the foreseeable future.

This comes about at the same time as an important staff change. Dir T D V Swinscow who for five years has given such excellent service as our Technical Editor is now giving this up. It is a pleasure to record the gratitude of the Annals to Dr Swinscow for his outstanding contribution - and to welcome Mrs Valerie Crean as his successor.

H L F C 